\title{
Relações governamentais, lobby e advocacy no contexto de public affairs
}

\author{
Governmental relations, lobby, and advocacy \\ in the context of public affairs
}

\section{Relaciones gubernamentales, lobby y advocacy en el contexto de public affairs}

Eduardo Carlos Ricardo da Patri

- Administrador de empresas formado pela Fundação Getúlio Vargas de São Paulo (FGV-SP)

- Sócio fundador e diretor da Patri Políticas Públicas, Relações Institucionais e Governamentais

- Sócio fundador e diretor da Patri Inc. - Brazilian Government Relations Company, de Washington, DC, Estados Unidos

- Membro associado ao Public Affairs Council (PAC) e à American League of Lobbyists (ALL), em Washington

- Prestador de serviços a grandes empresas multinacionais estrangeiras e brasileiras, bem como a entidades de classe e confederações empresariais, inclusive em modelagem organizacional

- Participante ativo nos fóruns de discussão para a regulamentação interna destas atividades e para o combate à corrupção

- eduardo.ricardo@patri.com.br 
Este texto não é exatamente um artigo acadêmico, mas algo resultante de uma experiência profissional nesta área em vinte e cinco anos no país e quinze no exterior - especialmente no mercado norte-americano e na União Europeia. O que aqui se discute é se, na prática, existem diferenças significativas entre relações governamentais, advocacy e lobbying. Ou trata-se apenas de atividades resultantes de uma evolução histórica, na qual uns e outros "se acomodam" na real busca da defesa de seus legítimos interesses? Conclui-se indicando que uma nova era para assuntos públicos ou public affairs se inicia após a grave crise financeira - econômica e fiscal - de 2008 e o advento da massificação das mídias sociais como o Facebook e o Twitter.

PALAVRAS-CHAVE: POLÍTICAS PÚBLICAS • MODELAGEM INSTITUCIONAL • RELAÇÕES GOVERNAMENTAIS • ADVOCACY

- LOBBYING • PUBLIC AFFAIRS

Abstract

This text is not exactly an academic article, but rather something that results from a professional experience in this area developed in the course of twentyfive years in-country and fifteen abroad - particularly in the U.S. market and in the European Union. What one discusses here is if in practice there are significant differences between government relations, advocacy and lobbying. Or does it only concern the activities that result from a historical evolution, in which some individuals "become remiss" in the true quest for defense of their legitimate interests? One concludes by suggesting that a new era for public issues or public affairs begins after the serious economic and fiscal financial crisis of 2008 and the advent of massification of social media like the Facebook and Twitter.

KEYWORDS: PUBLIC POLICIES • INSTITUTIONAL MODELING • GOVERNMENT RELATIONS • ADVOCACY • LOBBYING • PUBLIC AFFAIRS

\section{Resumen}

Este texto no es exactamente un artículo académico, sino algo resultante de una experiencia profesional en esta área durante veinticinco años en el país y quince en el exterior, especialmente en el mercado norteamericano y en la Unión Europea. Lo que aquí se discute es si, en la práctica, existen diferencias significativas entre government relations, advocacy y lobbying. ¿O se trata apenas de actividades resultantes de una evolución histórica, en la cual unos y otros "se acomodan" en la real búsqueda de la defensa de sus legítimos intereses? Se concluye indicando que se inicia una nueva era para los asuntos públicos o public affairs tras la grave crisis financiera (económica y fiscal) de 2008 y la llegada de la masificación de los medios sociales como Facebook y Twitter.

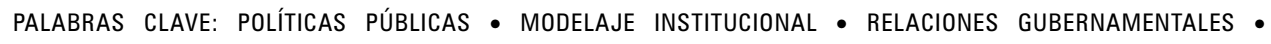
ADVOCACY • LOBBYING $\bullet$ PUBLIC AFFAIRS 
Este certamente não é um artigo acadêmico, mas algo resultante de uma Lexperiência profissional nessa área em vinte e cinco anos no país e quinze no exterior - especialmente no mercado norte-americano e na União Europeia. Ao longo desse período, tentamos continuadamente aprender, prestar serviços, ensinar, e mais do que isto não defender atividades com imagem tão desgastada, mas tentar desconstruí-las, trilhando um novo caminho realmente profissional. Discutimos se na prática existem diferenças significativas entre government relations, advocacy e lobbying ou se se trata apenas atividades resultantes de uma evolução histórica, na qual uns e outros "se acomodam" na real busca da defesa de seus legítimos interesses. Concluímos indicando que uma nova era para assuntos públicos ou public affairs se inicia após a grave crise financeira - econômica e fiscal - de 2008 e o advento da massificação das mídias sociais como o Facebook e o Twitter.

\section{UM POUCO DE HISTÓRIA}

República (do latim res publica, "coisa pública”) é uma forma de governo na qual o chefe do estado é eleito pelos cidadãos ou seus representantes (Dicionário, 2010). O que caracteriza uma república é a sobreposição do bem público ao bem privado, sacrificando-se as vantagens pessoais pelo bem comum. Ou seja, o fundamento da república é a virtude.

Democracia (do grego demos = povo e kratía = governo) é o sistema político em que a autoridade emana do conjunto dos cidadãos, baseando-se nos princípios de igualdade e liberdade, governo do povo. Ou seja, o povo de um país pode participar da vida política. Essa participação pode ocorrer por meio de eleições, plebiscitos e referendos. Dentro de uma democracia, as pessoas possuem liberdade de expressão e manifestações de suas opiniões (Dicionário, 2010).

Renato Janine Ribeiro (2001a), em seu livro A democracia, nota que a grande diferença entre a democracia antiga e a moderna foi a cisão entre os direitos individuais e os coletivos, que retirou o conteúdo social encerrado na democracia antiga. Esses direitos foram sendo repostos lentamente com a concessão dos direitos políticos, no século XIX, e dos direitos sociais, no século XX. Na república moderna, nascida com o capitalismo, a virtude é substituída pelo interesse, conforme o autor, que afirma que hoje em dia se respeita o bem público, separando-o da propriedade privada, não mais por amor à pátria, mas por interesse, o qual se reflete nos ganhos que a fixação de regras estáveis traz em longo prazo. Na opinião de Ribeiro, a chave para reduzir a distância entre a república ideal e a real encontra-se na educação e na natureza flexível dos homens que pode ser moldada para estimular a autodisciplina dos indivíduos e sua participação na vida social. 
A tese dos dois livros de Janine ${ }^{1}$, conforme resumo do próprio autor, é que

a república funciona pela vontade, e a democracia, pelo desejo. A democracia expressa o desejo por mais. Bem orientado, esse desejo se converte em direito à igualdade, de bens, de oportunidades ou perante a lei. Já a república consiste na necessidade ou obrigação de refrear o próprio desejo, a fim de respeitar um bem comum que não é o patrimônio de uma sociedade por ações, mas o cerne do convívio social.

Partindo dessa visão, passemos à questão da república e da democracia no Brasil.

A República proclamada em 1889 no Brasil não pode ser considerada uma república democrática uma vez que foi exercida por 41 anos sem a participação do povo e, pior, sem preocupações sociais. Em 1930, houve uma ruptura na República e um violento processo de urbanização, que fez do Brasil, em cinquenta anos, um país urbano. Podemos dizer que, nessa época tivemos o início da democratização política da República. Em 1946, a nova constituição brasileira reintroduz a democracia no contexto político brasileiro com o fim do autoritarismo do Estado Novo e a devolução da soberania política ao voto popular.

Surge então, com grande força, o populismo, que consolidou a imagem de um líder soberano, e as camadas populares se entregaram a quem demonstrava, por meio de ações políticas e simbólicas, o seu compromisso com as massas. A força do populismo deu margem ao desenvolvimento da esquerda e isso nos levou, em 31 de março de 1964, ao golpe militar, que perdurou por 21 anos, fazendo-nos viver sob uma ditadura. A primeira conclusão importante a que chegamos é que o Brasil teve períodos curtos de democracia, nos quais não houve sequer tempo de consolidar seus fundamentos na sociedade brasileira.

Em 1985, conseguimos, mais uma vez, instituir novamente a democracia no Brasil. E, passados 26 anos, ainda estamos aprendendo e nos familiarizando com os fundamentos e as ferramentas a serem utilizadas pela sociedade para que ela possa não só participar do processo de formação de políticas públicas, mas também construir uma democracia mais forte e consolidada. A ferramenta mais importante para se consolidar uma democracia é a participação popular, que pode dar-se de diversas formas.

$\mathrm{O}$ voto, geralmente, é o primeiro ato que nos vem à mente. Ele atrai a atenção pública, especialmente quando a mídia cobre as campanhas feitas para eleger nossos representantes. Mas, apesar de o voto ser extremamente importante este não é o único ato pelo qual os cidadãos podem exercer sua influência política. Estes podem fazer parte de organizações políticas, grupos de interesse, as-

1 Renato Janine Ribeiro é autor também de $A$ república (2001b). 
sociações de classe etc. Mas, para expressar suas opiniões, o fazem por meio do ato de advogar ou da defesa de interesses, que se traduz em diversas formas.

\section{CONTEXTO}

Relações governamentais, advocacy e lobbying inserem-se em um contexto maior do processo de formação das políticas públicas e de public affairs ou assuntos públicos. Políticas públicas, de uma forma simples e objetiva, podem ser definidas como ações que o governo, representando o estado, decide fazer ou não, dentre as alternativas propostas, tomadas a serviço do interesse público ou coletivo da sociedade. Implicam alterações de comportamento, planejamento, criação e implementação de leis, normas ou incentivos que visem atender às demandas e interesses da sociedade. O processo de elaboração das políticas públicas envolve as seguintes fases:

- Formação da agenda, por meio da seleção das prioridades.

- Formulação de políticas, por meio da apresentação de soluções ou alternativas para o problema em questão.

- Tomada de decisão, por meio da escolha de ações em respostas aos problemas.

- Implementação, por meio da execução das ações.

- Avaliação, por meio de um dinâmico e permanente processo de aferição dos resultados obtidos versus os custos incorridos.

Nós, latinos, temos que entender que políticas públicas não são apenas aquelas de caráter social ou voltadas para as minorias. Não há nada de necessariamente errado em relação às políticas públicas que visem dar maior competitividade à indústria, ampliar nossa infraestrutura, eliminar as defasagens históricas na correção das tabelas de imposto de renda para as pessoas físicas etc. Também devemos compreender que em políticas públicas não existe o win-win, ou uma solução na qual todos sairão ganhando, algo falacioso e hipócrita, recorrente nos nossos processos decisórios: sempre existirão ganhadores e perdedores. Já o processo e a formação das agendas públicas, sejam elas globais, nacionais, estaduais ou municipais, envolvem uma constante contraposição ou um alinhamento entre as agendas expostas pela opinião pública versus mídia e as agendas do governo - administração pública.

Quem são os partícipes destes processos de políticas públicas? De um lado, os representantes da sociedade civil ou opinion makers, sejam eles os atores, formadores de opinião, grupos de interesse e grupos de pressão, compostos por cidadãos, eleitores, contribuintes, entidades empresariais, entidades sindicais, organizações não-governamentais, acadêmicos, representantes das diversas religiões, raças e minorias, think tanks e watchdogs. Do outro lado, os representantes do estado ou decision-makers, sejam eles funcionários públicos, burocratas, gestores públicos, representantes políticos com mandato popular, 
políticos influentes ainda que sem mandato popular, exercendo suas funções "nos mais diversos poderes institucionais" - executivo, agências reguladoras, autarquias, fóruns e conselhos administrativos, legislativo, judiciário, e ministério público - e "nos mais diversos níveis administrativos" - global (por meio dos organismos internacionais), federal, estadual e municipal.

Questionamos a chamada independência entre os poderes, os quais na realidade são interdependentes e deveriam atuar segundo os interesses coletivos maiores, da sociedade, e não exercer "autoridade" sobre a mesma, uma vez que o estado emana do povo, deriva da sociedade, e não deve tentar submetê-la.

Esse conjunto acaba resultando, quando vivemos em um sistema político democrático, em um processo de formação de políticas públicas com múltiplos players, em diversas instâncias e poderes. Em uma jovem democracia como a que ora vivenciamos - uma vez que a Constituição Brasileira de 1988 sequer completou 25 anos - acaba por ser entendida por muitos como desorganizada, quando na realidade se trata de um sistema cada vez mais complexo, participativo, com muitos atores e decisores, ao qual denominamos processo decisório atomizado.

Antes de se fazer uso de qualquer ferramenta de defesa de interesse, é necessário que consolidemos a noção de lógica temática ou transversalidade - as discussões sobre elaboração e implementação de políticas públicas passam pelos diversos entes da sociedade civil e pelos poderes executivo, legislativo, judiciário e pelo ministério público. Além disso, há que se firmar o conceito de lógica administrativa ou verticalidade por meio dos níveis global, federal, estadual e municipal. Veja-se o gráfico 1.

Gráfico 1 - Transversalidade e verticalidade entre sociedade organizada e administração pública

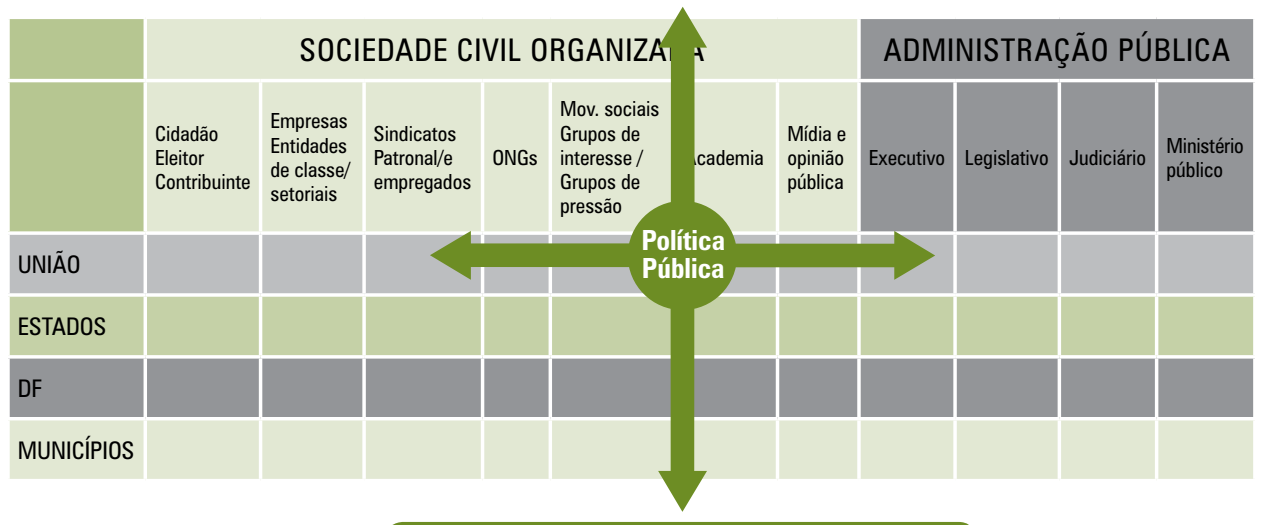

AVALIAÇÃO ESTRATÉGICA 
É incrível como grande parte da chamada elite brasileira, composta pelas classes A e B, quer solução política para tudo, critica a tudo e a todos, sem a menor noção de edificação institucional, de modus operandi em temos de políticas públicas, sem o menor interesse participativo. O que nos anima é que a "nova sociedade brasileira", emergente da década passada ${ }^{2}$, paralelamente à crescente mobilidade social e espacial ou geográfica, busca novos hábitos de vida e de consumo, novos hábitos de participação cada vez mais ativa nesses processos públicos: em 2014 provavelmente $60 \%$ da nossa população será composta por integrantes da chamada classe $\mathrm{C}$ havidos por novas políticas públicas em prol do bem comum.

Participar conscientemente do processo de formação das políticas públicas é exercer a cidadania. A democracia é algo que se constrói e se consolida no dia a dia, ao longo de muito tempo. Há alguns anos costumo afirmar que "na democracia, o processo de formação das políticas públicas demanda participação de todos os segmentos da sociedade civil, informação confiável, representação qualificada, transparência e ética". A evolução nessa direção é silenciosa, lenta, mas vez mais perceptível e significativa.

\section{A MODELAGEM INSTITUCIONAL}

A modelagem institucional brasileira, de um lado, pode ser descrita de forma simplificada por meio dos seguintes níveis e "atos":

- Global, por meio de convenções e tratados

- Federal:

- Constitucional

- Infraconstitucional,- leis complementares e leis ordinárias

- Normativa,-- decretos, resoluções, normas, portarias, atos etc.

- Estadual:

- Constituição estadual

- Infraconstitucional - leis complementares e leis ordinárias estaduais

- Normativa - decretos, resoluções, normas, portarias, atos, estaduais

- Municipal:

- Lei Orgânica do Município

- Leis municipais - complementares ou ordinárias

- Normas municipais - decretos, resoluções, normas, portarias e atos

Ou, por outro lado, essa modelagem institucional brasileira ainda pode ser apresentada por meio do gráfico 2:

2 Como está bem descrito em A pequena grande década: crise, cenários e a nova classe média (Nery, 2010). 
Gráfico 2 - Modelagem institucional brasileira

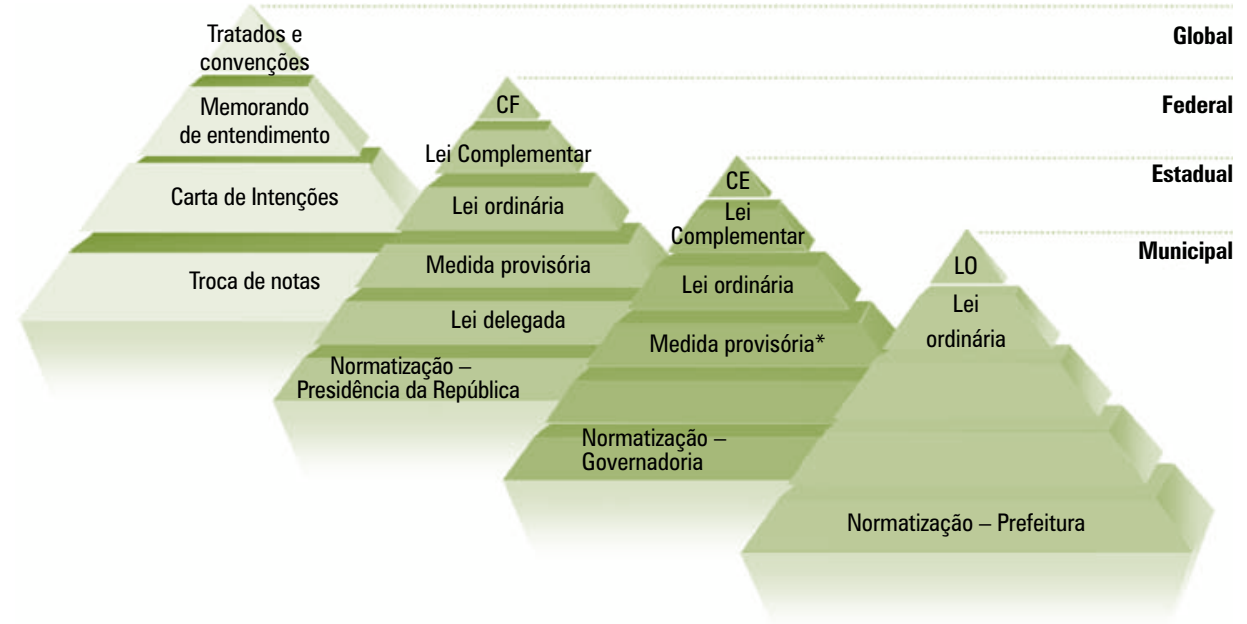

* Algumas constituições estaduais permitem a edição de medidas provisórias pelo chefe do poder executivo estadual

Devemos ter em mente que essa modelagem discutida entre 1986 e 1988, fruto do processo de redemocratização do país, baseia-se no sistema topdown, privilegiando e concentrando o poder de forma desbalanceada ao nível da União e particularmente no poder executivo. A Constituição Brasileira de 1988 - uma obra ainda inacabada - define quais são as competências privativas e concorrentes de cada ente administrativo, ou seja: o que compete apenas à União legislar e o que ela deve fazer conjuntamente com os estados e os municípios; o que cabe apenas aos estados legislar e o que devem fazer conjuntamente com os municípios; e finalmente o que compete apenas aos municípios legislar.

Portanto, antes de discutirmos sobre cada um dessas políticas públicas, é fundamental que os atores, formadores de opinião e decisores - denominados policy makers - tenham uma noção de competência, ou seja, de quem é a responsabilidade de elaborar esta ou aquela política pública e os caminhos que a mesma percorrerá até a sua aprovação e implementação. Assim, dependendo da abrangência da política pública que está sendo discutida, esta passa por discussão em diversos níveis, ou seja, nos níveis global, federal, estadual e municipal. Por exemplo, quando discutirmos políticas públicas sobre educação, de maneira simplificada, deveremos ter em mente o que se expõe no gráfico 3.

Vale ressaltar que não temos no Brasil um bom sistema oficial de indexação de marco regulatório constitucional, infraconstitucional e normativo e, em especial, uma hierarquização rígida e realmente praticada para o sistema normativo, tornando qualquer processo de pesquisa e avaliação regulatória extremamente complexo. 


\section{Gráfico 3 - Competências dos policy makers}

COMPETÊNCIA PRIVATIVA

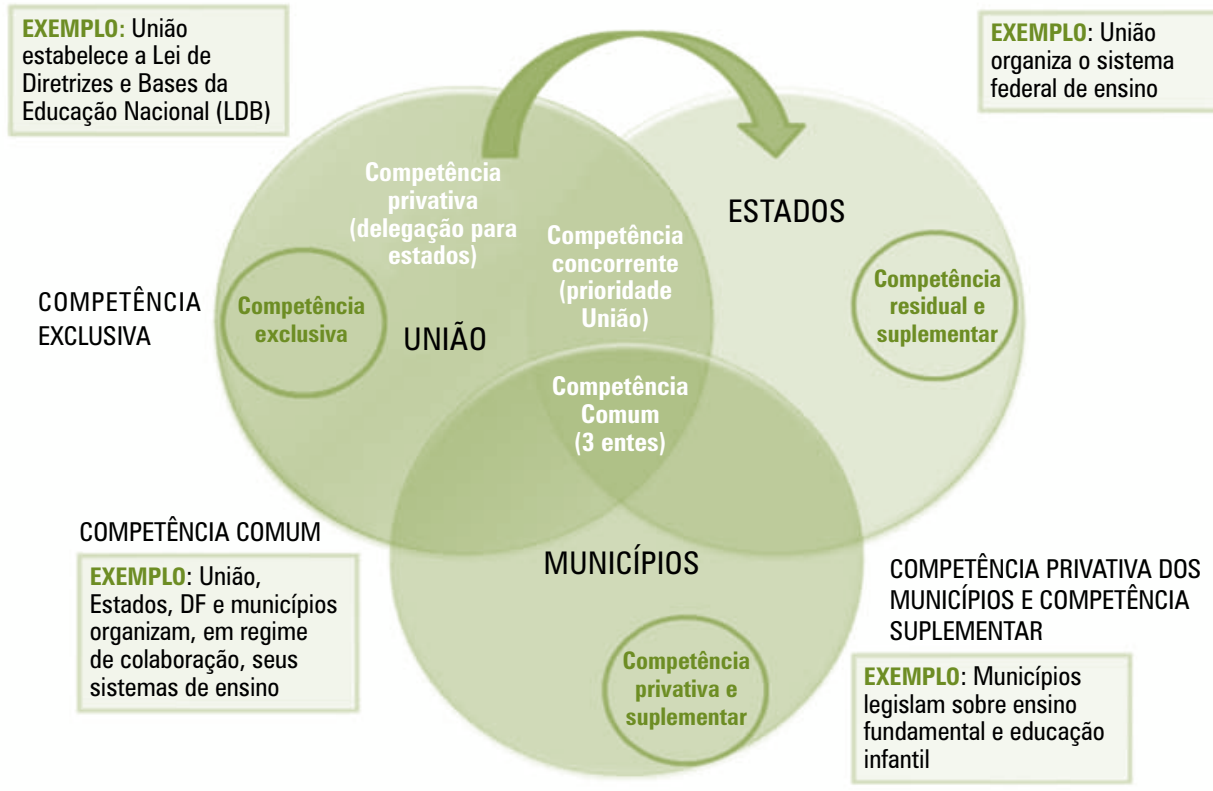

\section{O QUE É PUBLIC AFFAIRS}

Trabalhando nessa atividade, nos identificamos muito com as teses defendidas pelo Public Affairs Council (PAC), baseado em Washington, uma entidade composta por pessoas com expertise nessas atividades e interessadas em divulgar boas práticas profissionais.

Public affairs representa o esforço organizacional para monitorar e gerenciar seu ambiente de negócios. Isso combina relações governamentais, comunicação, gerenciamento de temas e estratégias de cidadania corporativa - responsabilidade socioambiental - para influenciar políticas públicas, construir uma forte reputação e buscar um solo comum com os stakeholders.

É a arte de evitar crises. Um programa de public affairs ou assuntos públicos envolve necessariamente não apenas conhecer, mas desenvolver e criar sinergias entre: metas da campanha; estratégia de relações governamentais; estratégia de grassroots ou mobilização; estratégia de financiamento de campanhas eleitorais; Public relations - estratégia de comunicação pela mídia tradicional e mídia social; estratégia de alianças, associações e coalizões; responsabilidade social; estratégia de mensagens fundamentais para educação e convencimento. 
Public relations, parte integrante de public affairs, pode ser entendida como a prática para gerenciar o fluxo de informações entre a organização e seus públicos, em uma definição bem ampla. Historicamente, a assessoria de imprensa evoluiu para assessoria em comunicação, desta para public relations, envolvendo stakeholders, internos e externos, opinion makers e decision-makers. Nos países mais avançados, as public relations trabalham com um campo muito maior do que apenas a comunicação interna e externa - seja ela para o público em geral, para consumidores e clientes, ou para decision-makers. $\mathrm{Na}$ realidade, elas monitoram, planejam, executam, interagem com os diversos stakeholders, por meio de várias ferramentas de trabalho e mídias de relacionamento, de forma a compor bases e alianças sólidas para o desenvolvimento e suas atividades específicas.

Em outra frente, em termos de public affairs, historicamente o lobbying evoluiu para advocacy e em seguida para government relations.

\section{MUNDO PÓS-2008 DIANTE DESTA NOVA DÉCADA}

Temos um "novo ponto de partida significativo e básico": segundo as percepções mais expressivas das pessoas, o mundo mudou após 2008, pelas seguintes razões: o capitalismo passou a ser considerado "irresponsável"- açodado ela busca de resultados e bônus; os governos foram irresponsáveis do ponto de vista fiscal - fruto de uma bonança exagerada; o neocapitalismo está "arquivado ou sobrestado" por alguns anos; a regulação por meio do estado está voltando à cena de maneira cada vez mais forte; há uma explosão das mídias virtuais - redes sociais ativistas e não mais sociais; os consumidores e clientes "votam" todos os dias, o dia todo; existe uma pressão pela adoção de políticas públicas que interessem aos cidadãos, consumidores, clientes - eleitores ou não - mas cada vez mais jovens e twitteiros.

Public affairs - antes entendido apenas como "negócios públicos" - o conceito está evoluindo rapidamente após a crise de 2008, somado à massificação da internet e das mídias sociais, para assuntos públicos. Isso em relação tanto ao cidadão, eleitor, contribuinte, atores, formadores de opinião, grupos de interesses e grupos de pressão da sociedade civil, quanto aos decision-makers (burocratas, gestores públicos ou representantes políticos). Tal fato implica não apenas um novo discurso ou approach, mas, principalmente, a reestruturação de áreas organizacionais, sistemas, ferramentas de trabalho, serviços e produtos.

Qual o real espectro de atividades dessa nova área de public affairs ou de assuntos públicos? Podemos relacionar as seguintes: processo educacional e de treinamento para convencimento; mapping dos stakeholders, relações com os clientes e/ou consumidores; alianças e coalizões; relacionamento com entidades de classe; organizações não-governamentais (ONGs), formadores de opinião, atores, grupos de interesse e grupos de pressão; processos de mobi- 
lização, formação de políticas públicas, regulamentações; preocupação com a formação de imagem e opinião pública, bem como com a responsabilidade socioambiental, a ética e a governança; comunicação - mídias tradicionais e mídias virtuais/redes sociais; relações governamentais, advocacy e lobbying; inteligência voltada para o desenvolvimento do negócio; eventos aplicados; gerenciamento de crises; financiamento de campanhas eleitorais.

\section{DEFESA DE INTERESSES}

A defesa de um interesse individual ou coletivo no processo de formação de políticas públicas pode ser feita por meio de uma série de ferramentas legítimas. Com elas os indivíduos ou a coletividade organizada podem expor opiniões, anseios, temores e informações técnicas que, além de informar os envolvidos na elaboração das políticas públicas, os ajuda a ter uma visão mais completa do impacto que suas decisões irão ter na sociedade.

Assim, se formam grupos de interesse para monitorar ações governamentais sobre determinado tema, como impostos (www.quantocustaobrasil.com.br), meio ambiente (www.socioambiental.org), ética (os caras-pintadas), o que ocorre em uma comunidade (Associação de Moradores do Chapéu - Mangueira), dentre outros. Essa formação de grupos para resolver problemas de natureza social ou civil é uma novidade no Brasil, mas nos Estados Unidos, pode ser observado com grande intensidade já desde 1834 conforme relatou Alexis de Tocqueville (1980, p. 191).

Grupos de Interesse muitas vezes surgem de movimentos sociais que representam as demandas de um grande segmento da população por mudanças na política, economia ou no próprio sistema social.

Há diversos tipos de grupos de interesse, entre os quais: os que representam os mais importantes setores da economia (CNT, Abifina, CNI, Fiesp, Abipla etc.); os que representam os interesses dos cidadãos em geral (por exemplo, a Associação Brasileira de Proteção aos Animais); e os que representam os interesses do comércio internacional e dos governos estrangeiros (Câmara de Comércio Americana, Câmara Espanhola etc.).

Grupos de interesse, assim como indivíduos ou empresas, empregam uma variedade de técnicas e estratégias para promover seus interesses ou suas políticas. Apesar de poucos grupos terem força suficiente para conseguir que o Congresso Nacional e o poder executivo incorporem totalmente suas políticas e interesses na agenda do governo, muitos conseguem modificar, retardar ou mesmo impedir a aprovação de uma legislação ou regulamentação apresentando informações, dados técnicos e a visão do lado que será impactado pelas ações governamentais. 
Para o jornalista Antônio Augusto de Queiroz (2008), diretor de Documentação do Departamento Intersindical de Assessoria Parlamentar (Diap), "em todas as democracias, as pessoas físicas e/ ou jurídicas se organizam, sob a forma de grupo de pressão, para legitimamente, defender seus interesses perante os poderes constituídos". Ele prossegue dizendo que "os grupos de pressão são fundamentais para a democracia porque podem contribuir para o aperfeiçoamento das políticas públicas; estabelecer limites à ação dos poderes; promover o interesse público em favor de determinados pleitos”.

\section{RELAÇÕES GOVERNAMENTAIS, ADVOCACY E LOBBYING}

Relações governamentais é o processo de gerenciamento das diversas etapas e ferramentas de trabalho para a defesa de interesses:

- Monitoramento das iniciativas de políticas públicas que positivamente ou negativamente afetem seus interesses.

- Avaliação inicial do mérito, para classificação em termos de prioridades.

- Avaliação de timing para reação ou ação.

- Avaliação processual.

- Pesquisa de dados e informações.

- Identificação do marco regulatório e prováveis impactos futuros.

- Avaliação completa do mérito.

- Definição do objetivo.

- Pesquisa e monitoramento das propostas congêneres.

- Identificação dos aliados e oponentes.

- Construção de argumentos ou advocacy: dados, estatísticas, pareceres, impactos etc.

- Identificação dos pontos negociáveis e dos pontos não negociáveis.

- Construção de coalizões e alianças.

- Definição da estratégia, envolvendo mensagens, normas e timings processuais, caminhos críticos.

- Busca de suporte na sociedade civil - formadores de opinião, atores, grupos de interesse, mídia, pesquisas de opinião pública.

- Formulação e implementação de um trabalho de comunicação pública.

- Identificação dos gestores da administração pública e os decisores.

- Identificação de alternativas ou o chamado plano B.

- Definição do plano de ação.

- Ação ou lobbying - parta para o trabalho de convencimento, com suporte técnico, representatividade ampla, e com base local.

Trabalhar essas ferramentas de modo a obter sinergia para o resultado pretendido não é uma tarefa tão fácil como alguns gostariam de acreditar. As técnicas utilizadas para atingir esses objetivos podem ser divididas em diretas e indiretas. 


\section{Ações indiretas - Advocacy}

As técnicas indiretas são utilizadas para influenciar o governo ou o Congresso Nacional por meio de terceiros, ou seja, dos eleitores ou do público em geral. Elas tendem a mascarar o real interesse por trás das ações, fazendo parecer que as demandas são espontâneas. Entre as ações indiretas temos:

- Geração de pressão pública pela mobilização de indivíduos por meio de anúncios em revistas, jornais, e-mails, televisão e demonstrações públicas. A internet tornou ainda mais fácil a mobilização dos indivíduos. Alguns grupos fazem pesquisas de opinião para saber como a sociedade vê determinado assunto e depois as publicam e divulgam pela internet atingindo um número maciço de pessoas. O objetivo dessa ação é o de convencer os elaboradores de políticas públicas de que a opinião pública está a favor da posição daquele grupo de interesse.

- Gerenciamento da imagem de empresas ou grupos de interesse. Neste caso, necessariamente não há uma vinculação a um tema político específico. Patrocinar eventos, contribuir com programas de televisão e anúncios exaltando as virtudes destes são algumas das técnicas para se gerenciar a imagem de um grupo ou uma empresa. Empresas e grupos de interesse tendem a acreditar que, construindo uma boa imagem, se consegue ter menos opositores aos seus pleitos.

- Utilização de eleitores como lobistas: por meio dessa técnica, o grupo de interesse tenta mobilizar um grande número de eleitores de uma determinada região com o intuito de fazê-los escrever cartas, enviar e-mails ou telefonar para os deputados e senadores eleitos por eles.

- Por fim, grupos de interesses ainda podem fazer uso de técnicas diversas das citadas acima, tais como marchas, desobediência civil ou demonstrações públicas.

\section{Ações diretas - Lobbying}

No caso das técnicas diretas, os grupos de interesse, os indivíduos ou as empresas se aproximam pessoalmente dos membros do governo ou do Congresso Nacional, para apresentar argumentos favoráveis ou contrários a determinada política ou legislação que esteja em discussão, ou seja, defendem seus interesses por meio do lobbying.

A palavra lobbying teve origem nos Estados Unidos por volta de 1800, quando indivíduos se aglomeravam nos lobbies dos hotéis de Washington, para fazer pedidos aos membros do Congresso Nacional em prol de ou contra 
leis em discussão. Diversas atividades configuram o ato de fazer lobbying. Entre elas podemos citar:

- Audiências com membros do governo ou do Congresso Nacional com o objetivo de apresentar o ponto de vista de um indivíduo, uma empresa ou um grupo em relação a uma legislação ou política pública específica.

- Participar de audiências públicas para expressar opinião favorável ou contrária à legislação em discussão.

- Apresentar sugestões para redação de uma legislação.

- Prover informação política para membros do Congresso Nacional ou do governo a respeito de como se apresenta o cenário em relação ao assunto em pauta.

- Acompanhamento e estatística de votação de projetos de lei por parlamentares.

- Financiamento de campanhas.

Outra técnica direta muito utilizada por grupos de interesse é a formação de coalizões com outros grupos com objetivos similares em relação a determinada legislação ou política pública. Coalizões dividem os custos e multiplicam a influência dos grupos que a formam, unindo seus poderes. Carlos Zarattini (2007), deputado federal paulista do Partido dos Trabalhadores (PT), um dos proponentes da regulamentação dessa atividade traz as seguintes definições no PL n ${ }^{\circ}$ 1202/2007:

- Lobby ou pressão: esforço deliberado para influenciar a decisão administrativa ou legislativa em determinado sentido, favorável à entidade representativa de grupo de interesse, ou de alguém atuando em defesa de interesse próprio ou de terceiros, ou em sentido contrário ao interesse de terceiros.

- Lobista ou agente de grupo de interesse: o indivíduo, profissional liberal ou não, a empresa, a associação ou entidade não-governamental de qualquer natureza que atue por meio de pressão dirigida ao agente público, seu cônjuge ou companheiro ou sobre qualquer de seus parentes, colaterais ou afins até o segundo grau, com o objetivo de dobrar a tomada de decisão administrativa ou legislativa favorável ao grupo de interesse que representa ou contrária ao interesse de terceiros quando conveniente ao grupo de interesse que representa.

O lobby, ou defesa de interesses, não pode mais ser discutido como virtude ou pecado, algo social e politicamente correto ou condenável, uma ferramenta apenas utilizada pelo poder econômico; é algo mais presente em nosso cotidiano do que pensamos ou gostamos de admitir.

Outra distinção comum de técnicas de defesa de interesse resume-se à divisão entre lobbying e advocacy. Apesar de, por diversas vezes, encontrarmos o uso 
indiscriminado dessas expressões como se significassem uma única coisa, a doutrina costuma defini-las de forma diferenciada.

Lobbying refere-se especificamente ao ato de advogar para tentar influenciar uma legislação específica. É dividido em grassroots lobbying - quando é feito um apelo ao público em geral para que este contate o governo ou membros do Congresso Nacional a respeito de uma legislação específica; e lobbying direto - quando o contato com o governo ou os membros do Congresso Nacional é realizado diretamente.

Advocacy, por sua vez, é o ato de advogar, exercido pelas organizações sem fins lucrativos, quando estas defendem seus próprios interesses, tentam influenciar algum aspecto da sociedade ou quando estes apelam para indivíduos para que mudem seus comportamentos, empregadores mudem suas regras ou o governo mude suas leis.

Como nos Estados Unidos existe uma legislação que controla a atividade encontramos uma interessante definição do que vem a ser lobbying e grassroots lobbying no regulamento do imposto de renda. Lobbying direto é a tentativa de uma organização de influenciar uma legislação quando a comunicação é direcionada a um legislador ou funcionário de uma organização legislativa, referindo-se a uma legislação específica e, ainda, refletindo uma opinião a respeito da legislação. E grassroots lobbying é a comunicação endereçada ao público em geral, referindo-se a uma legislação específica e refletindo uma opinião a respeito dela, para encorajá-lo a fazer algo em relação a ela.

No Brasil, os direitos de se manifestar livremente, de se associar e de peticionar ao governo estão todos garantidos na Constituição Federal de 1988.

Com isso, chegamos à conclusão de que todos os atos e todas as técnicas que descrevemos neste trabalho são legítimos, fazem parte do processo democrático e, sobretudo, constituem-se em meios pelos quais a sociedade de forma geral ganha voz e pode expressar seus anseios e temores. A única coisa que não é legítima é a falta de transparência, a falta de regulamentação para que os verdadeiros e sérios profissionais possam ajudar com informações, com organização e com experiência.

Government relations, advocacy, lobbying, lobby direto e indireto são atividades em constante evolução. Na prática confundem-se aqui e no exterior. Nesta nova década de 2010, elas deverão estar cada vez mais inseridas no contexto de assuntos públicos ou public affairs, no qual os cidadãos manifestam seus "votos" de maneira crescente pelas mídias sociais, questionando os conceitos de representação política até agora existentes. 


\section{CONSIDERAÇÕES FINAIS}

Somos totalmente favoráveis à revisão legal e à criação de um marco regulatório mais claro e rígido para:

- O acesso às informações públicas, com maior transparência para os cidadãos.

- Revisão das normas de revolving doors, com o aumento do prazo de carência para que ex-funcionários públicos em cargos de confiança passem a trabalhar na iniciativa privada.

- Revisão das normas que permitem a funcionários públicos em licença para fins particulares passem a prestar serviços à iniciativa privada.

- Responsabilização civil e criminal da pessoa jurídica, de seus diretores e controladores em atos de corrupção oriundos das suas relações com o setor público.

- Aprovação de lei para regulamentar as atividades de lobbying no país, nos mais diversos poderes e níveis administrativos.

\section{REFERÊNCIAS}

DICIONÁRIO. Dicionário da Língua Portuguesa (Acordo Ortográfico). Porto, Portugal: Porto Editora. Verbetes "democracia" e "república".

NERY, Marcelo Côrtes (Coord.). A pequena grande década: crise, cenários e a nova classe média. [Sumário executivo]. Rio de Janeiro: CPS-FGV, 2010).

QUEIROZ, A. Augusto. Transparência: lobby, democracia e acesso à informação. In: SEMINÁRIO INTERNACIONAL SOBRE INTERMEDIAÇÃO DE INTERESSESA REGULAMENTAÇÃO DO LOBBY NO BRASIL, Brasília, 2008. Anais... Brasília: CGU-OCDE,

TOCQUEVILLE, Alexis de. Democracy in America. Vol. 1 New York: Knopf, 1980. p.191

RIBEIRO, Renato Janine. A democracia. São Paulo: Publifolha, 2001a.

A república. São Paulo: Publifolha, 2001b.

ZARATTINI, Carlos. PL n 1202/2007: disciplina a atividade de "lobby" e a atuação dos grupos de pressão ou de interesse e assemelhados... Brasília: Câmara dos Deputados, 30 maio 2007

Recebido em: 13.06.2011 / Aceito em: 13.07.2011 